\title{
Research of Small Valley Towns Based on Spatial Syntax Taking Xuecheng as an Example
}

\author{
Chen Hong, Yulu Ya, Tinghua Hu, Xiaoqing Hu, Xianmin Mai* \\ Southwest MinZu University, Chengdu, China \\ Email: *648826495@qq.com
}

How to cite this paper: Hong, C., Ya, Y. L., Hu, T. H., Hu, X. Q., \& Mai, X. M. (2019). Research of Small Valley Towns Based on Spatial Syntax Taking Xuecheng as an Example. Current Urban Studies, 7, 449-458.

https://doi.org/10.4236/cus.2019.73022

Received: May 6, 2019

Accepted: September 22, 2019

Published: September 25, 2019

Copyright $\odot 2019$ by author(s) and Scientific Research Publishing Inc. This work is licensed under the Creative Commons Attribution International License (CC BY 4.0).

http://creativecommons.org/licenses/by/4.0/

\begin{abstract}
Small towns are a transitional existence between traditional villages and modern cities, and an important buffer for reconciling urban-rural binary contradictions. At present, China has entered a period of rapid urbanization. The state has introduced a series of policies such as urban-rural integration, urban-rural integration, and new rural construction to promote the development of small towns. This study selected Xuecheng Town, Li County, Aba Prefecture as the research object, and used space syntax to do research on spatial logic. At the same time, combined with the actual public space conditions of river valley-type small towns, the paper puts forward some planning suggestions for optimizing the layout of public space and public facilities in small valley towns, and provides theories and methods for its improvement, so that the planning resources input in western Sichuan can be effectively utilized.
\end{abstract}

\section{Keywords}

Spatial Syntax, Spatial Logic, Small Valley Town, Street Vitality

\section{Introduction}

\subsection{Research Background}

Small towns are a transitional existence between traditional villages and modern cities, and an important buffer for reconciling urban-rural binary contradictions. At present, China has entered a period of rapid urbanization (Zheng, 2013). The state has introduced a series of policies such as urban-rural integration, urban-rural integration and new rural construction to promote the development of small towns. With the country's focus on the construction of small towns, small towns have become an important target in the study of various academic fields such as humanities and architecture. In recent years, the academic work on 
small towns has achieved certain results. However, the research focuses on the empirical analysis, induction and interpretation of urban space, but lacks the basis of spatial quantitative research, and it is difficult to obtain scientific quantitative results and certainty laws (Zhang, 2017).

\subsection{The Goal and Purpose of Research}

Using the relevant theoretical methods of spatial syntax, based on the quantitative analysis results of integration degree, integration degree, connection value, control value, depth value, and penetration degree in public space, combined with the actual public space situation of the case valley-type small towns (Yuan, 2015), it proposes planning suggestions for optimizing the layout of public space and public facilities in small valley towns, providing theory and methods for its improvement, so that the planning resources input in western Sichuan can be effectively utilized.

\section{An Example}

This study selected Xuecheng Town, Li County, Aba Prefecture as the research object, and used space syntax to do research on spatial logic. On the basis of the existing actual basic data, the space of the case towns will be explored in detail, and the relevant data will be collated and analyzed and summarized.

Xuecheng Town is located 23 kilometers northeast of the county. It is connected to Muka Town in the east, Puxi Town in the south, Shangmeng and Xiamen in the west, and Weicheng Town in Maoxian in the north. The whole town covers an area of 258.3 square kilometers. The town is located at $103^{\circ} 13^{\prime}$ east longitude, $31^{\circ} 33^{\prime}$ north latitude, and 1647.7 meters above sea level in Xuecheng. It belongs to the mountain dry valley and semi-arid valley climate zone. It has four distinct seasons, short winter and summer, cool in winter and cool in summer, with an average annual temperature of $12.5^{\circ} \mathrm{C}$, frost-free period of 220 days, rainfall of $489.2 \mathrm{~mm}$. Xuecheng Township is an administrative division of Li County, located 23 kilometers northeast of the county seat and 180 kilometers away from the provincial capital Chengdu. Xuecheng Town is located in the center of Sixiang Town. The transportation is convenient. National Highway 317 passes through the town. It connects Li County, Wenchuan County and Aba Prefecture Capital, and connects Mengxiang and Xiameng Township through Xuemeng Highway. The "Ningjiang Gate" in the town of Xuecheng Town was built in the second year of Qing Emperor Qianlong (Aba Prefecture Government of Sichuan Province, 2010). It is about 4 meters high and about 2 meters wide. It is now Aba State-level cultural relics protection unit.

\section{The Improved Method}

\subsection{Data Research Method}

On the basis of the existing actual basic data, the space of the case towns will be explored in detail, and the relevant data will be collated and analyzed and sum- 
marized. The research mainly uses research methods such as literature research method, field research method, questionnaire survey method, mathematical analysis method and topological analysis method.

The study sorts out the existing basic data, conducts field research to investigate the current situation of public space in small towns, and finds out the existing problems in the layout of public space and public service facilities through the investigation of the status quo. And using the relevant theoretical methods of spatial syntax, combined with the computer Depthmap software (Zhao, 2014), the spatial logic of the public space of the case study object is studied separately.

\subsection{Analysis of the Atmosphere and Street Space of Xuecheng Street}

The field investigation and research covers 8 major streets including Jiaochang Road and West Street. The following four steps were carried out: labeling the name of the road in Xuecheng Town; measuring the length and width of the road and the height of the house; looking for the center of the town, mainly observing several points in the town where the flow of people is large, and the number of pedestrians grouped on the street per unit time. (Government, commercial street, restaurant); mark the location of urban public service facilities. The survey found that there are many crowd activities on School Road, West Street and Ximen Street.

The activities of people in the two time periods from 8:00 to 10:30 in the morning and from 16:00 to 18:30 in the afternoon were active. Less activity after dark.

\subsubsection{The Function of Xuecheng Street}

The street function of Xuecheng is mainly based on living streets. On both sides of the street are residential buildings, administrative services, public service facilities, and shops for business transactions. Most of the residents were residents and aborigines who moved after the earthquake. At the same time, the advantage of living on both sides of the street is that it can provide enough street use for the street, and it can also enhance the vitality of the street; its street functions are mixed.

For example, in the Jiaochang road with many crowd activities, its two sides are mixed with commercial functions, as well as administrative office functions (Figure 1(a)), which bring convenience to people's lives (Figure 1(b). Another example is West Street, which has a relatively high level of activity (Figure 1(c)). The residential building on one side is mixed with business, the two-storey building in the Qiang style has a bottom line, and the other side is mixed with educational land (Figure 1(d)).

\subsubsection{Street Space of Xuecheng Street}

Appropriate street scales (such as street length, width and street $\mathrm{D} / \mathrm{H}$ value), street greening and street furniture will affect people's activities to a certain extent. The width of Xuecheng Street is as small as 1.8 meters, up to 10 meters, and 


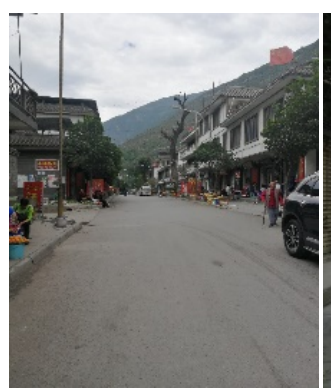

(a)

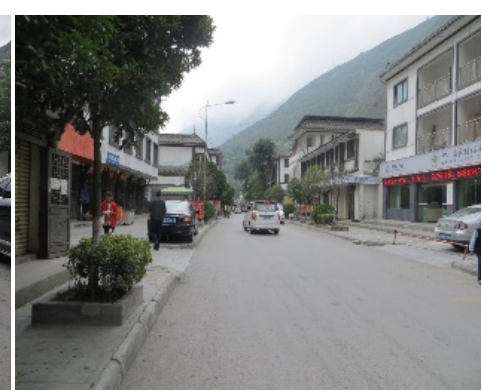

(b)

the buildings are mostly two or three stories high. Compared with the two streets of National Highway North District and East Street, National Highway North City $(1.8 \mathrm{~m})$ and East Street $(5 \mathrm{~m})$, the side building is basically a two-story building, serving residents on both sides. The width and height of the East Street street is more comfortable, and there are more people on the street.

Awara Yoshito once discussed greening: greening in the city is logically justified (Yoshishin, 2006). Visually, green can create a quiet atmosphere (Yoshishin, 2006). From the color point of view, the blue of the sky and the green of the trees are calm colors, which can calm people and get rest and relaxation ( $\mathrm{Li} \& \mathrm{Hu}$, 2017: pp. 6-15). As the center of the town, the school road is the main road for life and transportation in Xuecheng (Figure 2(a)). In order to make people stay, there will be tree pools (Figure 2(b)) and flower beds on both sides of the street, so that people will not feel bored when they walk on the road. Similarly, there are certain street facilities that can also drive people's activities. There are fewer street facilities in Xuecheng. Street seats, fitness equipment, floor coverings, sculptures, sketches, etc. are rare. East Street is equipped with a small number of seats that can be rested (Figure 2(c)). When it comes to commuting and going to school, you can see that the staff, students and people who are going to work nearby will sit down and chat. There will be no one to stay in Ximenwai Street and National Road North City.

\subsubsection{Street activities in Xuecheng Street}

As a mixed area of Tibetan, Yi and Han nationalities, Xuecheng's work is relatively

Figure 1. (a) Jiaochang road; (b) Credit union; (c) Kindergarten in West Street; (d) Qiang style building.

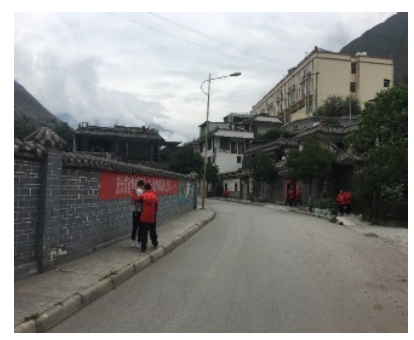

(a)

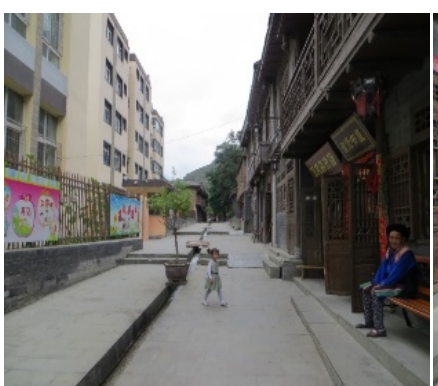

(c)

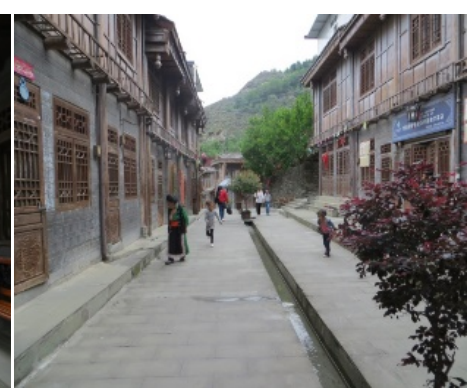

(d)

Figure 2. (a) Students coming home from school figure; (b) Tree pool on the school road figure;

(c) Pedestrian stay in East Street.

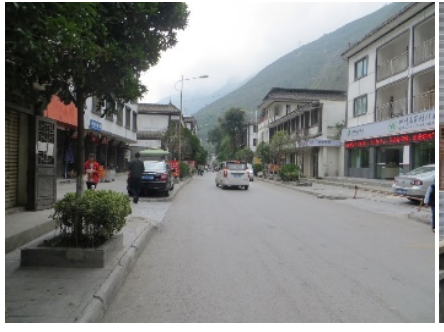

(b)

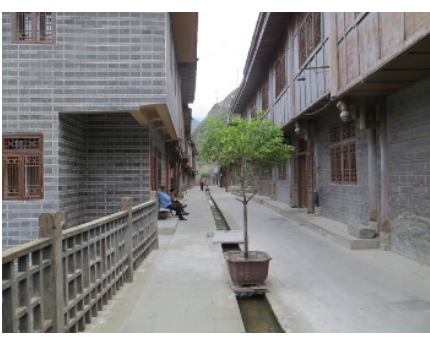

(c) 
leisurely. Xuecheng Street is mainly based on residential functions, and the necessary activities take place in the morning and evening. There are more activities in the morning and evening periods. At other times, the streets are quiet. It coincides with the low season of tourism and the working day. There are fewer pedestrians and tourists on the street.

\subsubsection{Field Street Survey Data}

The scope of the on-site investigation and research includes 8 main streets including Jiaochang Road and West Street. Due to the limitations of research equipment and research time, it is impossible to obtain the stay and activities of all people on the street at the same time. Unless all the scenes on the street can be recorded at a relatively high point, the current equipment and technical conditions cannot be achieved. Therefore, the survey method we adopted was based on the number of pedestrians photographed per unit time on the street. In the two working days from July 24 to 25,2018 , the survey will be divided into three time periods: 8:00-10:30, 12:00-14:30, and 16:00-18:30. During the time period, the group went through the surveyed streets and completely recorded the pedestrian activity on the streets during that time period. Finally, the photographed photos are objectively and accurately compiled with statistical flow data. Data information is shown in Table 1.

\section{Result}

Summary: After the axis model is successfully established, the corresponding value is calculated. According to the results of syntactic calculation, it can be seen that each value of Xuecheng is within the scope of research that can be controlled. The data is presented in Table 2.

\section{Discussion}

Combined spatial syntactic analysis.

\subsection{Xuecheng Connection Value}

The connection values of several streets in Xuecheng Town are Ximenwai Street: 3.26996; Jiaochang Road: 2.43672; West Street: 0.359155; National Highway North District: 1.1107; South Henan Road: 0.959486; National Road: 3.06638;

Table 1. Human traffic statistics.

\begin{tabular}{cccccccccc}
\hline \multirow{2}{*}{ time } & \multicolumn{2}{c}{$\begin{array}{c}\text { East Main } \\
\text { Street }\end{array}$} & $\begin{array}{c}\text { National Highway } \\
\text { North City }\end{array}$ & $\begin{array}{c}\text { South Huanshan } \\
\text { Road }\end{array}$ & $\begin{array}{c}\text { Covered } \\
\text { bridge }\end{array}$ & $\begin{array}{c}\text { West } \\
\text { Avenue }\end{array}$ & $\begin{array}{c}\text { Ximenwai Street } \\
\text { g Road }\end{array}$ & \multicolumn{3}{c}{$\begin{array}{c}\text { Jiaochan Xue Meng Along Henan } \\
\text { Road }\end{array}$} \\
\hline June 24, 20188:00-10:30 & 7 & 3 & 2 & 0 & 15 & 10 & 56 & 0 & 3 \\
June 24, 201812:00-14:30 & 1 & 3 & 4 & 0 & 3 & 28 & 20 & 0 & 5 \\
June 24, 201816:00-18;30 & 0 & 8 & 4 & 2 & 20 & 15 & 18 & 0 & 1 \\
June 25, 20188:00-10:30 & 9 & 3 & 5 & 1 & 23 & 13 & 21 & 3 & 0 \\
June 25, 201812:00-14:30 & 17 & 1 & 1 & 0 & 20 & 6 & 29 & 0 & 0 \\
\hline
\end{tabular}


Table 2. The main spatial characteristics of Xuecheng Town.

\begin{tabular}{cccc}
\hline Attribute & Minimum value & Maximum value & average value \\
\hline Connectivity & 0.359155 & 3.26769 & 1.763580 \\
Choice & 0.115152 & 0.91784 & 0.397136 \\
Intergration [HH] & 9.1171 & 32.9043 & 22.1413 \\
Node Count & 81 & 81 & 81 \\
Line Length & 6.356 & 541.729 & 182.695 \\
Mean Depth & 4.03636 & 6.96364 & 5.495453 \\
\hline
\end{tabular}

Figure 3. Xuecheng connection value.

Huanshan South Road: 1.02874; Xue Meng Road: 1.88711 (Figure 3).

In the analysis of the connection degree, the value of one section of Ximenwai Street is relatively high, and it is in a conspicuous position in the analysis of the whole connection degree. Secondly, the connection value of the field road connected with Ximenwai Street is relatively high. High, and the connection value of the security bridge and Xue Mengqiao is also relatively high. The results of the analysis are consistent with the actual distribution of the main street and its nodes in the ancient town. The security bridge and Xuemeng Bridge connect the towns on both sides of the Zagunao River and become the main traffic nodes. There are residential buildings and Xuecheng Junior High School, Xuecheng Primary School and Xuecheng Kindergarten on both sides of Ximenwai Street. There are residential buildings and office buildings, markets and stations in different departments on both sides of the road. The traffic of the segment is relatively large, which is roughly consistent with the results of the analysis. However, the flow of people in the field is significantly larger than that of Ximenwai Street (Figure 3).

\subsection{Xuecheng Selection Value}

The selection values of several streets in Xuecheng Town are 0.91784 in Ximen- 
wai Street; Jiaochang Road: 0.482115; West Street: 0.426936; National Highway North District: 0.230044; Yannan Road: 0.115152; National Road: 0.611448; Huanshan South Road; 0.122172; Xue Meng Road: 0.27138 (Figure 4).

The degree of choice indicates the potential of a space to attract traffic (Hillier \& Hanson, 1984: pp. 12-24). In the analysis of the degree of selection, the value of Ximenwai Street is the highest. In the actual research process, as the central street of the whole town, Ximenwai Street is connected to the Jiaochang Road and the Security Bridge. It is the entire town's traffic receiving center, so its traffic attraction is great, and the syntactic analysis is consistent with the actual situation (Figure 4).

\subsection{Xuecheng Integration Value}

The integration values of several streets in Xuecheng Town are Ximenwai Street: 26.8437; Jiaochang Road: 29.0672; West Street: 13.69907; National Highway North District: 17.699; South Henan Road: 19.7622; National Highway: 32.9043; South Huanshan Road: 9.1171; Xue MengRoad: 28.0442 (Figure 5).

The degree of integration reflects the extent to which a single space is concentrated or discrete between all other monomer spaces in the system (Hillier \& Hanson, 1984: pp. 12-24). The area where Ximenwai Street and Jiaochang Road are located constitutes the main part of the development of Xuecheng Ancient Town. It is a living street developed by Xuecheng Town since ancient times and is also the core area for the development of ancient towns.

From the number and distribution of the red to yellow axis, the area with strong traffic access in Xuecheng Ancient Town is concentrated in the center of the ancient town of Xuecheng. From the syntactic point of view, the most central area (Huang, 2013: pp. 5-8), its location penetration and integration The strongest force, the town has grown from then on (Figure 5).

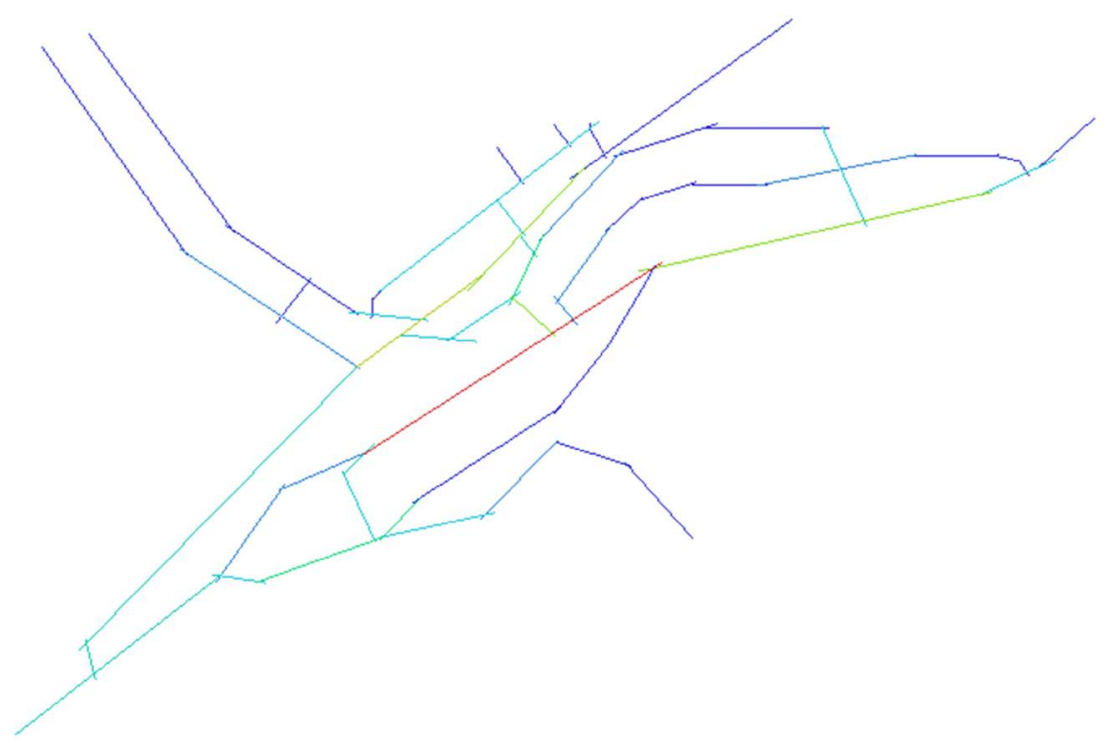

Figure 4. Xuecheng selection value. 


\subsection{Average Depth Value}

The average depth values of several streets in Xuecheng Town are: Ximenwai Street: 4.03636; Jiaochang Road: 4.61818; West Street: 6.96364; National Highway North District: 6.25455; South Henan Road: 5.72727; National Highway: 5.03636; Huanshan South Road: 6.89091; Xue MengRoad: 4.43636 (Figure 6).

The smaller the average depth value, the more convenient the location of the node is, and the closer the relationship with other nodes is, the larger the average depth value is, the more secret the geographic location is, and the more distant the connection with other nodes (Velvet, 2017: p. 6). From the red to the blue area, the accessibility of the axis is getting stronger and stronger. It can be seen from the average depth map of Xuecheng's axis that the development space of Xuecheng is extremely organized. Ximenwai Street and Jiaochang Road have relatively small scores in the analysis of the global average depth value. In addition, the

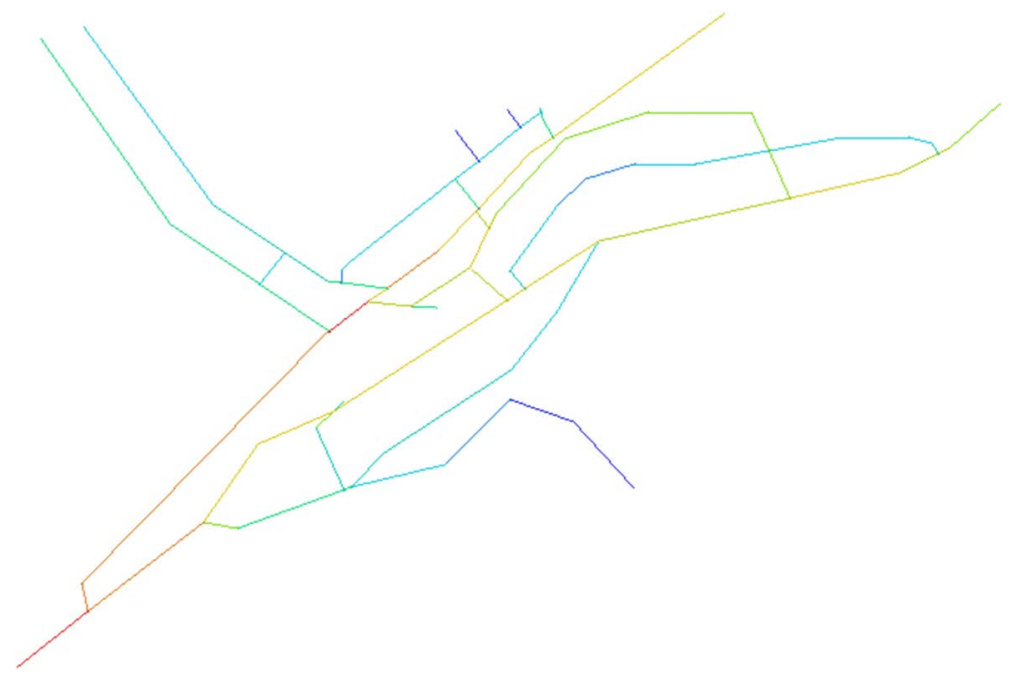

Figure 5. Xuecheng integration value.

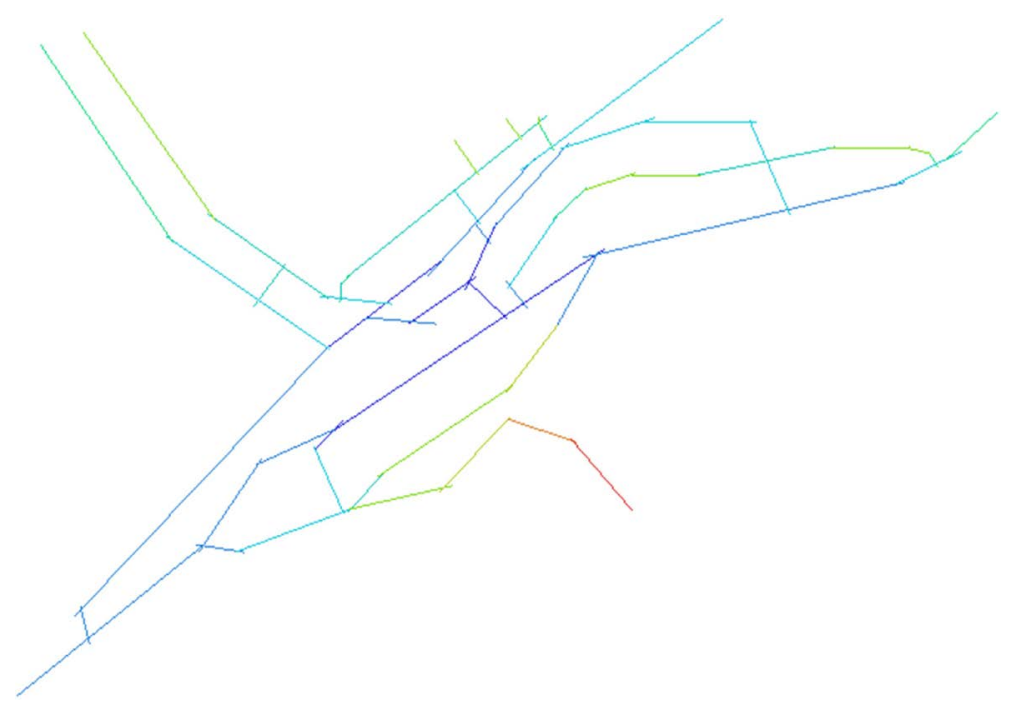

Figure 6. Xuecheng average depth value. 
average depth value of National Highway 317 is relatively small. The $317 \mathrm{Na}$ tional Road passes through Xuecheng Town and passes through the Xuecheng Section of National Highway 317. The flow rate is relatively large, so the depth value is relatively high; and Ximenwai Street and Jiaochang Road are the central streets of Xuecheng Town. Therefore, according to the actual research results, the analysis results are basically consistent with the actual ones.

\section{Conclusion}

\subsection{Summary of Main Characteristic Values of Xuecheng Town}

Based on the main and line characteristic values of the connection, degree of selection, integration degree and average depth of the above-mentioned Xuecheng ancient town, the spatial logic of Xuecheng Town is distinct, the central axis is highly connected, the topological steps are shallow, and the integration is relative in the central area. The higher the average depth is, the higher the selectivity in the whole Xuecheng activities, the lower the spatial connectivity of the secondary axis, the deeper topological steps, the lower relative integration, the lower activity selectivity and the lower average depth. Combined with the logical structure, it can be seen that the spindle space in Anju Town is transparent, the sub-axis space interface is rich, the internal guiding and circulation are high, and it is easy to form a residential area.

\subsection{Space Promotion Advice}

Maintain the characteristics of the ancient town and set up characteristic space nodes.

The ancient town of Xuecheng has a long history. After the Wenchuan earthquake, most of the houses in the ancient town were reconstructed after the earthquake. The villages that were originally distributed in different places were resettled in Xuecheng Town by way of neighboring residence and street formation. Although the historical relics of Xuecheng Ancient Town have been preserved in the earthquake, their overall spatial pattern has changed more or less. In actual research, the reality of most of the public space in Xuecheng is not satisfactory. It seems that the residents do not often gather in the existing public space, because the public space is not set according to the living habits of the original residents, so the characteristics of the existing public space in Xuecheng are not prominent.

Therefore, when improving the quality of Xuecheng public space, it can be combined with the characteristics of Xuecheng nationality to create and distinctive public spaces in suitable nodes. The public space is kept in harmony with the overall scale of the ancient town.

\section{Conflicts of Interest}

The authors declare no conflicts of interest regarding the publication of this paper. 


\section{References}

Aba Prefecture Government of Sichuan Province (2010). Planning of Jingchang Village Boutique Tourism Village in Xuecheng Town, Li County.

Hillier, B., \& Hanson, J. (1984). The Social Logic of Space (Vol. 1, pp. 12-24). Cambridge: Cambridge University Press.

Huang, Z. (2013). A Study on the Spatial Syntax of the Formation of Ancient Towns in Hunan Province (pp. 5-8). Changsha: Hunan University.

Li, Y., \& Hu, A. (2017). Analysis of the Design of Taikooli Commercial Pedestrian Street in Chengdu from the Aesthetics of the Street. Architecture and Culture, No. 6, 6-15.

Velvet, W. (2017). Spatial Logic Analysis of Traditional Mountain Settlement in Chongqing-Based on Space Syntax Theory. Chongqing: Chongqing Normal University.

Yoshishin, A. (2006). Street Aesthetics. Tianjin: Baihua Literature and Art Publishing House.

Yuan, Y. (2015). Research on the Development of Small Towns in China from the Perspective of Urban-Rural Integration. Jinan: Shandong University.

Zhang, X. (2017). Study on the Syntax of Typical Traditional Villages in Shandong Based on Topographical Features. Jinan: Shandong University.

Zhao, Q. Z. (2014). Research on Public Service Facilities Planning of Farm-Type Tourism Small Towns in Heilongjiang Province. Harbin: Harbin Institute of Technology.

Zheng, W. (2013). Study on the Living Space of Small Towns under the Condition of Urban and Rural Integration. Chengdu: Southwest Jiaotong University. 